\title{
The Double Omohyoid Muscle in Humans: Report of One Case and Review of the Literature
}

\author{
By \\ Masahiro MIURA, Seiji KATO, Ichiro ITONAGA and Takeshi USUI \\ Department of Anatomy, Oita Medical University, Oita, 879-55, Japan \\ - Received for Publication, March 24, $1995-$
}

Key Words: Accessory omohyoid muscle, Ansa cervicalis, Nerve supply, Gross anatomy

\begin{abstract}
Summary: An anomalous muscle was found in the right anterior cervical region of a 68-year-old Japanese man. The muscle was investigated anatomically, with special reference to its supply. Few such reports are available.

The anomalous muscle arose from the upper margin of the scapula as an aponeurotic sheet, ran medialocranialward and separated into the superficial and profound fasciculi at the lateral edge of the sternohyoid muscle. The former fasciculus was inserted into the lower border of the hyoid bone without fusing with adjacent muscles, or as an independent fasciculus. Meanwhile, the latter fasciculus incompletely fused with the lateral portion of the sternohyoid muscle. This muscle was supplied from its posterior surface and the upper edge by two slender nerves from the ansa cervicalis (roots of origin: $\mathrm{C1}, \mathrm{C2}$ and $\mathrm{C3}$ ).

Based on the nerve supply and a review of the literature, the muscle is discussed in terms of its true nature and its mechanism of formation. As a result of the investigation, this muscle is assumed to be a vestigial structure in humans reduced from the M. episterno-cleido-hyoideus sublimis (Fürbringer), which is observed in lower types of vertebrates (reptilies, etc.).
\end{abstract}

It is well known that various anomalous muscles often appear in the triangular area between the sternohyoid and omohyoid muscles. Statistical investigation by many researchers has shown that various human anomalous muscles (Macalister, 1871; Testut, 1884; Loth, 1912; Langsam, 1941; Mori, 1964; Sato, 1969). According to the status of origin, insertion and location of these muscles, the forms of various anomalies were classified into 5 types by Loth (1912), and later into 6 types (Fig. 1) by Yamada, H. (1960).

In the course of anatomical disection training for students of the Oita Medical University during the 1991 school year, the present authors happened to encounter a rare anomalous muscle, a so-called "accessory omohyoid muscle" (Yamada, S. 1934) which belongs to Type VI (Fig. 1) previously reported by Yamada, H. (1960). However, our muscle derived from the omohyoid muscle differed from the muscles in previous reports with respect to its origin and insertion. In spite of some findings related to the omohyoid muscle, the accessory omohyoid muscle has not yet been fully reported. In the present study, careful dissection mainly of its nerve supply was carried out in comparison with the anomalous muscle (Type VI) described in previous reports. This paper reports details of this muscle and discusses its true nature, from the topographical anatomical relationship to the pattern of its nerve supply.

\section{Materials and Methods}

An anomalous muscle was observed in the right cervical region of a Japanese male (Cadaver No. 359 ), who was 68 years old at the time of death due to bronchial asthma.

This muscle was found when the skin and the superficial fascia in the cervical region were removed and the sternocleidomastoideus muscle was cut off at its origin. After dissection of the cervical region and the cervical plexus, the external appearance of the infrahyoid muscles, especially the omohyoid and sternohyoid muscles, their innervation and the neighboring structures were recorded. Furthermore, this muscle and the omohyoid muscle were removed at the sites of their proximal and distal attachments to the scapula and the hyoid bone, respectively, to examine the nerve supply to each muscle. The nerve supply from the origin to the intramuscular distribution was observed using a binocular microscope. 

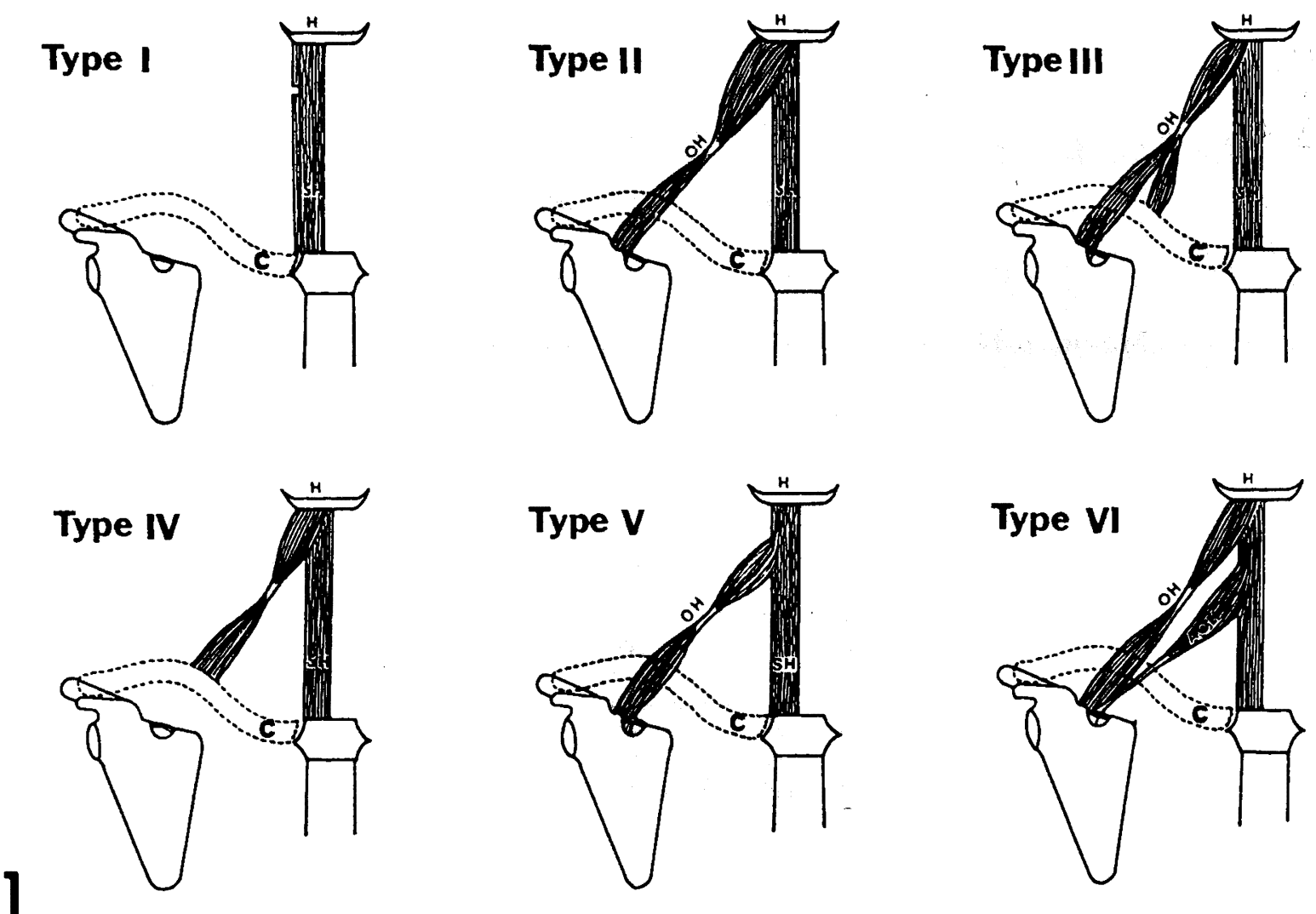

Fig. 1. The classification of the anomalous omohyoid muscle (Yamada's classification, 1960).

Type I: $\quad$ Absence of Omohyoid muscle (whole or part) and/or intermediate tendon.

Type II: $\quad$ Supernumerary bundles of Superior belly or both belleis duplication of whole muscle.

Type III: Abnormal pattern of Inferior belly (Inferior belly divided into two or three fasciculi).

Type IV: Cleido-hyoid muscle or Accessory cleido-hyoid muscle.

Type V: Abnormal pattern of Insertion of Omohyoid muscle (Shortening of Superior belly).

Type VI: Accessory omohyoid muscle (M. omohyoideus accessorius).

AC: ansa cervicalis

AOH: accessory omohyoid muscle

BP: brachial plexus

CCA: common carotid artery

C: $\quad$ clavicle

De: deltoid muscle

Di: $\quad$ digastric muscle (anterior belly)

F: facial artery

$\mathrm{H}$ : hyoid bone

IJV: internal jugular vein

IR: inferior root

Is: infraspinatus muscle

Ls: levator scapulat muscle

My: mylohyoid muscle

$\mathrm{OH}$ : usual omohyoid muscle

$\mathrm{OHI}$ : inferior belly of usual omohyoid muscle

OHS: superior belly of usual omohyoid muscle

PF:

PG:

PM:

R:

SA:
Explanation of Figures

Abbreviations

Sc:

ScA: scalenus anterior muscle

$\mathrm{Scm}$ : sternocleidomastoid muscle

SF: $\quad$ superficial fasciculus of the anomalous muscle

Sh: sternohyoid muscle

SpS: $\quad$ spine of scapula

SR: $\quad$ superior root

Ss: $\quad$ supraspinatus muscle

SsA: $\quad$ suprascapular artery

St: $\quad$ sternothyroid muscle

STSL: sup. transverse scapular ligament

SuA: subclavian artery

SV: $\quad$ subclavian vein

T: trapezius muscle

TA: tendinous arch

TCN: transverse cervical nerve

TG: $\quad$ thyroid gland

Th: thyrohyoid muscle

$\mathrm{X}$ : vagus nerve

XI: accessory nerve

XII: hypoglossal nerve 


\section{Findings}

Both the omohyoid and sternohyoid muscles were usual in origin, insertion and location. However, only on the right side, we found an anomalous muscle which seemed to be a duplication of the omohyoid muscle (Fig. 2).

The anomalous muscle arose as an apponeurotic sheet (about $11 \mathrm{~mm}$ in width) from the upper margin of the scapula and from the scapula notch in proximity to the medial side of the usual muscle (Figs. 3 and 4), and ran medialocranialwards collaterally with the usual muscle after becomming a cord-like tendon (about $3 \mathrm{~mm}$ in width) during its ascending course. This muscle passed into a relative abundance of muscle bundles (about $15 \mathrm{~mm}$ in maximum width) and then ran further upward to become two fasciculi (the superficial and profound fasciculi) at the distal portion of the muscle (Fig. 5). The superficial fasciculus of the distal bundles was found to enter into the lower border of the body of the hyoid bone as an independent fasciculus on the anterior surface of the sternohyoid muscle. In addition, this fasciculus was connected with small muscle fibers (about $2 \mathrm{~mm}$ in width) which were regarded as an aberrant bundle derived from the usual omohyoid muscle. Namely, this fasciculus arose from the medial margin of the superior belly of the usual muscle and joined with the lateral part of the distal one-third region of the superficial fasciculus. Meanwhile, the profound fasciculus incompletely passed into the middle part of the lateral portion of the sternohyoid muscle and formed a small tendinous arch (Figs. 5a and b, arrow). In overall length the anomalous muscle was $111 \mathrm{~mm}$ with a slender tendon of $2 \mathrm{~mm}$ wide and $45 \mathrm{~mm}$ long, especially the muscular portion was about $66 \mathrm{~mm}$ in length.

The general features and main branches of the cervical plexus were normal (Figs. 6a and b). Socalled "temporary adhesion" (Kikuchi, 1970) between the ansa cervicalis (AC) and the vagus nerve on the right side was clearly observed in the original regions of the origin of $\mathrm{AC}$. The manner of nerve supply was the medial type. The segments of its origin were $\mathrm{C} 1$, C2 and C3 (Fig. 6b).

Figure 7 shows the intramascular nerve distribution of all branches of the muscle. This muscle was supplied from two slender branches (A and B) derived from AC. The A branch arising from the superior root of AC gave oof two fine branches to the distal portion of an anomalous muscle at the level of the superior belly of the usual omohyoid muscle.

These branches were distributed in the distal portion of the muscle, that is, the lateral portion of the superficial and the profound fasciculi. But one of the fine branches took a reverse course, entering the superior belly of the omohyoid muscle, while the other entered into the distal one-third portion of the anomalous muscle (lateral edge). The filaments from the fine branches to the superficial fasciculus were seen in the bridge fasciculus from the superior belly of the omohyoid muscle. Furthermore, these filaments closely communicated with the others supplying the superior belly of the omohyoid muscle near the insertion regions (Fig. 7, asterisk**). The terminal filaments to the superficial fasciculus penetrated into the lateral portion of the anomalous muscle to emerge from between the profound fasciculus of the muscle and the sternohyoid muscle, and then entered into the anterior surface of the distal portion of the sternohyoid muscle.

On the other hand, the B branch arising from the inferior 'root of $\mathrm{AC}$ entered into the proximal one-third portion of the anomalous muscle on the posterior surface (Fig. 7) and was predominantly distributed to the proximal portion of the muscle. The filaments from the fine branches were also seen in the medial portion of the superficial fasciculus.

\section{Discussion}

\section{Rare abnormality as accessory omohyoid muscle}

The anomalous muscle found by the present authors arises from the scapula and inserts on the hyoid bone. This muscle arose from the scapula and inserted into the hyoid bone on the medial side of the usual omohyoid muscle. Therefore, it was named "M. omohyoideus alter" (Windle, 1887) or "M. omohyoideus accessorius" (Yamada, S., 1934).

In view of such origin and insertion, our muscle is assumed to be the accessory omohyoid muscle and can roughly be classified as Type VI (Fig. 1) presented by Yamada, H. (1960). Variations of this muscle with respect to origin, insertion and location have been reported. Figure 8 shows 6 types of the accessory omohyoid muscle, including our muscle. They can be further grouped as two subgroups with respect to the presence of tendon; one subgroup $(1,2)$ has an intermediate tendon and the other subgroup (36 ) has no tendon. Our muscle is somewhat similar to the muscle (Fig. 8, subtype 5) reported previously by Yamada et al. (1960) in that it originates from a tendon but has no intermediate tendon. However, the distal bundles of our muscle are separated into two fasciculi, the superficial and profound fasciculi. The superficial fasciculus inserts into the hyoid bone without fusing adjacent muscles at the anterior surface of the sternohyoid muscle. Meanwhile, all the other muscles fuse with the sternohyoid muscle in the middle part of their lateral border. Our muscle differs slightly from similar muscles reported previously 


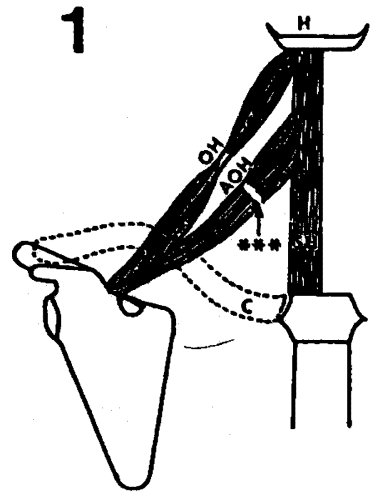

WINDLE (1887)

CHIBA et al. (1958) KUDOH et al. (1991)
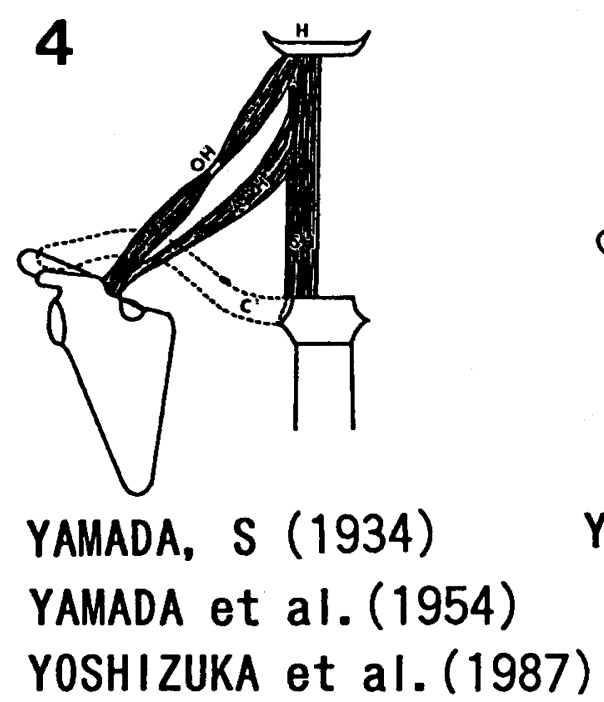

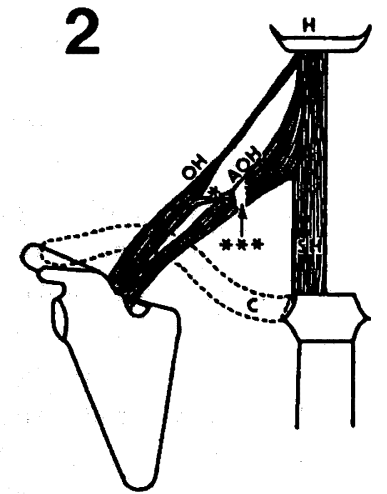

TOTINAl et al. (1944)

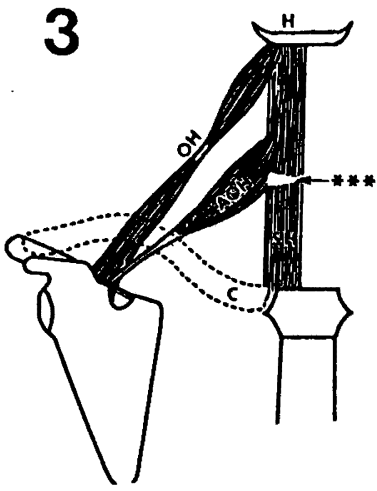

SASAGAWA (1982)

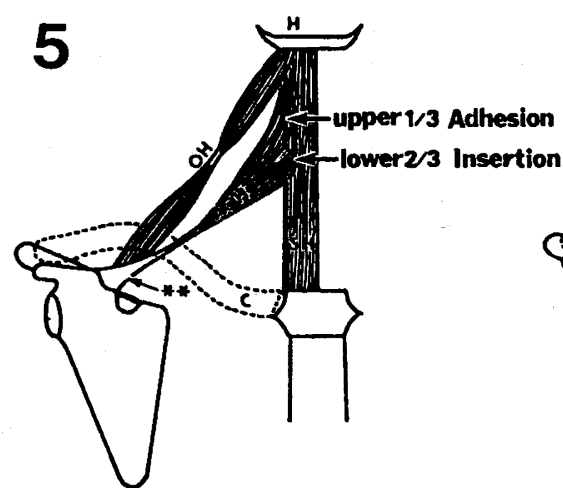

YAMADA et al. (1960) MIURA et al. (1995)

Fig. 8. Schematic drawing ot the accessory omohyoid muscle (belonging to Yamada's Type VI, 1960) which has hitherto been reported and classified roughly into 6 subtypes location, origin, insertion and state (ex, muscular portion or aponeurotic portion; intermediate tendon bridge fasciculus). Number 6 is our case. Only in this case, the superficial fasciculus is separated from the distal portion of an anomalous muscle, enters ventrally into the hyoid bone without fusing adjacent muscles in front of the sternohyoid muscle (or as an independent fasciculus). All of the above cases except Windle's one are found on the right side of the anterior region of the neck.

*: the bridge fasciculus, ${ }^{* *}$ : the aponeurotic portion, ${ }^{* * *}$ : the intermediate tendon.

with respect to the pattern of insertion. Consequently, it may be a very rare accessory omohyoid muscle that is an abnormality of the omohyoid muscle.

\section{Incidence of occurrence of accessory omohyoid muscle}

With regard to the incidence of the accessory omohyoid muscle of Yamada's Type VI in the Japanese, Yamada, S. (1934) found 2 cases $(0.8 \%)$ of this muscle on 250 body sides of fetuses and newborns. Totinai et al. (1944) discovered only 1 case $(0.16 \%)$ on 616 body sides of adults. Yonekura et al. (1954) also reported 2 cases $(2.0 \%)$ on 100 body sides of fetuses, without any explanation of this muscle. All the reports on this muscle cases except them were single case reports (Chiba et al., 1958; Yamada, H., 1954, 1960; Sasagawa et al., 1982; Yoshizuka et al., 1987; Kudoh et al., 1991). In addition, there have been no statistical investigations on the incidence of this muscle by non-Japanese investigators although they have reported many cases of anomalous omohyoid muscles since the first report 
of "M. omohyoideus alter" by Windle (1887).

\section{True nature of the accessory omohyoid muscle}

In research on the true nature of the accessory omohyoid muscle which appears in the triangular area between the sternohyoid and omohyoid muscles, phylogenetic analysis may be available. Lower types of mammalians, reptilians and amphibians have a plate-like muscle, the so-called episterno-cleidohyoideus sublimis (ECHS, Fürbringer, 1987), that arises on the anterior neck from the sternum, clavicle and scapula and inserts on the hyoid bone.

Gegenbaur (1876) and later Eisler (1912) described that anomalies of human infrahyoid muscles might directly be derived from one vast muscular sheet on the extending neck region. They considered that the omohyoid and sternohyoid muscles of mammals correspond to the differentiated ECHS muscle. Takano et al. (1955) also reported the omo-cleidosterno-hyoideus, which corresponds to the ECHS muscle (Fürbringer), from a human female fetus of 7 months of menstrual age (one case of 248 body sides; $0.40 \%$ ). Namely, in mammals, the middle part of the ECHS muscle, which is of clavicle origin, tends to be reduced, while the medial and the lateral parts tend to differentiate into the sternohyoid and omohyoid muscles respectively. Moreover, when the ECHS muscle is greatly reduced the absence of various infrahyoid muscles may occur. Conversely, when the middle part is slightly reduced, various anomalies may appear in the area between the sternohyoid and omohyoid muscles. Lewis (1960) recognized that in a $9 \mathrm{~mm}$ human embryo the rudiment of the neck muscles differentiates from the plate-like muscle, and that each infrahyoid muscle appears from the same anlage in the developmental process.

From the phylogenic standpoint (Gegenbaur, 1876) the nine previous investigators sited in Fig. 8 considered that their anomalous accessory omohyoid muscles were vestigial structures of the ECHS muscle, although no in detailed descriptions of the nerve supply were presented.

When a muscle retrogresses or disappears wholly or partially in the phylogenetic or ontogenical process, the nerve that supplies it may remain in its original location, and even if the motor nerve disappears, the sensory nerve at least tends to remain (Eisler, 1901 and 1912; Kasai, 1975; Kasai et al., 1977). Hence the true nature of the human accessory omohyoid muscle should be considered on the basis of the condition of its nerve supply. Gegenbaur (1876) found microscopically nerve fibers entering into the fascia in the human newborn. Furthermore, Eisler (1912) simply stated that the regular twigs given from the ansa hypoglossi were seen in the fascia in the develop- mental process of humans. Yamada, S. (1934), Yoshizuka et al. (1987) and Kudoh et al. (1991) only stated that this muscle is supplied by the twigs arising from AC. Thus, none of the available reports have examined the nerve supply of the human accessory omohyoid muscle. Accordingly, the present authors examined very carefully the regional distribution of $\mathrm{AC}$ over the fascia cervicalis enclosing the triangle area, and reflected the accessory omohyoid muscle, but no involuted branch from AC into the fascia could be unable to confirmed. Therefore, our muscle should more appropriately be regarded as a rudimentary structure of the ECHS muscle. That is, on the basis of the present findings of the nerve supply, it would appear that the distal portion of the muscle is an atavistic structure from the ECHS (Fürbringer) and that the aberrant bundle is derived from the medial portion of the superior belly of the usual omohyoid muscle during the process of ontogeny. Moreover, according to Nisi's theory of two (muscular) systems of the body trunk muscles and from the viewpoint of the nerve supply and the relationship with adjacent muscles, the distal portion of the muscle in this case can be closely related to the sternohyoid and the superior belly of the omohyoid muscle, and the distal portion of our muscle should be included in the rectus system of the ventral trunk muscles of the neck. On the other hand, the proximal muscular portion and the tendinous portion may be included in the "obliquus internus" system.

Nishi (1938) described that phylogenically the ventral trunk muscles of mammals are derived directly from those in reptiles. He further stated that each infrahyoid muscle (sternohyoid, omohyoid, sternothyroid and thyrohyoid) could be classified into two muscular systems of trunk muscules of the body from the standpoint of typical anatomy. Namely, he classified the infrahyoid muscles except the omohyoid muscle as the rectus muscular system, and classified only the omohyoid muscle as "the obliquus internus" muscular system of trunk muscles of the neck. Likewise, Steinbach (1923) cited Albrecht (1876) and noted that the sternohyoid muscle belongs to the rectus-system, and the omohyoid muscle to the obliquus (internus)-system. Moreover, Yamada, M. et al. (1985) suggested that the omohyoid and the other muscles of the infrahyoid muscles can be considered as two types possibly belonging to both muscular systems, the sternohyoid muscle to the rectus-system, and the omohyoid muscle to the obliquus-system.

Gegenbaur (1876) and Eisler (1912) considered that the infrahyoid muscles differentiated only from the rectus muscular system of the ventral trunk muscles of the neck. Therefore, according to their view it may be inferred that the ECHS muscle is 
composed only of the rectus muscular system. However, generally the muscle group belongs to anterior neck muscle, and it has been interpreted on the basis of Nishi's theory that the sternohyoid muscle belongs to the rectus-system, and the omohyoid muscle to the obliquus-system. We also agree with his theory based on our findings. For this reason, the ECHS muscle can be regarded as a complex formed with muscles from both the rectus and the obliquus internus muscular systems of the anterior neck muscles. In addition, it is assumed that the superior belly of the omohyoid muscle is closely related to the rectus muscular system of the anterior neck muscles in view of their nerve supply and the findings of previous investigators (Koura, 1960; Sato et al., 1969) on the locational relationship between the sternohyoid muscles and the superior belly of the omohyoid muscle. In connection with our view, the works of Takizawa $(1971,1973)$ on the development of the infrahyoid muscles of Anura during metamorphosis is worthy of mention. Concerning derivation of the omohyoid muscle, he has asserted that the superior belly belongs to the rectus muscular system, whereas the inferior one belongs to the obliquus muscular system.

On the basis of the above findings and discussion, we propose the following as the true nature and mechanism of formation of the accessory omohyoid muscle. The muscle may be a vestigial structure in humans reduced from the episterno-cleido-hyoideus sublimis (Fürbringer), which can be observed in lower types of vertebrates (reptilians, etc.). On the other hand, only the lateral portion of the superficial fasciculus of our muscle may be an aberrant bundle derived from the superior belly of the usual omohyoid muscle during the process of ontogeny.

\section{Acknowledgements}

The authors are grateful to Mr. T. Kajiwara for his skilled technical assistance, and to Miss K. Andoh for her secretarial help. We wish to thank Prof. Ryosuke Miyauchi, First Department of Anatomy, Fukuoka University School of Medicine, for his excellent guidance at the beginning of our study.

\section{References}

1) Albrecht P. Beitrag zur Morphologie des M. omohyoideus und der ventralen Interbranchialmuskulatur in der Wirbeltiere. Kiel. (cited from Steinbach)

2) Buntine JA. The omohyoid muscle and fascia: Morphology and Anomalies. Aust. N. Z. J. Surg. 1970; 40:86-88.

3) Chiba I, Ogawa T, Onodera $H$, Toshibe $T$, Saijoh $T$, Saitoh $F$ and Saitoh M. Abnormal muscles of sternohyoid and omohyoid. Iwateidai kaibou gyouseki. 1958; 3:87-92. (in Japanese)

4) Eisler P. Der M. sternalis, seine Uxsache und Entstehung, nebst Bemerkungen zwischen Nerv und Muskel. Zeitschr. f. Morph. und Anthrop. 1901; 3:21-92.

5) Eisler P. Muskeln des Halses, Musculi colli. Die Muskeln des Stammes. 234-342, Gustav Fischer, Jena, 1912.

6) Fürbringer $M$. Ueber die spino-occipitalen Nerven der Selachier und Holocephalen und ihre vergleichende Morphologie. 1897; 3:349-778.

7) Gegenbaur C. Ueber der Musculus omohyoideus und seine Schlüsselbeinverbindung. Morphol. Jahrb. 1876; 1:243-265.

8) Kasai T. Morphological characteristics of the Achselbogen muscle and its degenerative processes. Acta. Anat. Nippon. 1975; 50:47. (in Japanese abstract)

9) Kasai $T$ and Chiba $S$. True nature of the muscular arch of the axilla and its nerve supply. Acta Anat. Nippon. 1977; 52:309-336. (in Japanese with English abstract)

10) Kikuchi T. A contribution to the morphology of the ansa cervicalis and the phrenic nerve. Acta Anat. Nippon. 1970; 45:242-281.

11) Koura I. An anatomical study of muscles of the neck in Japanese. J. Oral. Anat. 1960; 14:147-180. (in Japanese with English abstract)

12) Kudoh $\mathbf{H}$ and Kida $M$. A case of duplicated omohyoid muscle with an accessory slip of sternothyroid muscle. Acta Anat. Nippon. 1991; 66:323. (in Japanese abstract)

13) Langsam CL. M. omohyoideus in American whites and negroes. Am. J. Phys. Anthropol. 1941; 28:249-262.

14) Lewis WH. The development of the muscular system. Keibel F \& Mall FP, Manual of human embryology, 1st ed., 454-522, Lippincott, Philadelphia, 1910.

15) Loth E. Muskeln des Halses. Beiträge zur Anthropologie der Negerweichteile, 58-73. Streker \& Schröder, Stuttgart, 1912.

16) Loth E. Muscle du cou. Anthropologie des parties molles. Masson \& Cie. 71-97, Paris, 1931.

17) Macalister A. Additional observations on muscular anomalies in human anatomy (Third series) with a catalogue of the principal muscular variations hitherto published. Transact. Roy. Irish Acad. 1871; 25:1-134.

18) Mori M. Statistics on the Musculature of the Japanese. Okajimas Folia Anat. Jpn. 1964; 40:195-300.

19) Nishi S. Muskeln des Rumpfes. Bolks Handbuch der vergleichenden Anatomie der Wirbltiere. Bd.V 351-446, Urban und Schwarzenberg, Berlin, u. Wicen, 1938.

20) Nishi S. Topologische Anatomie des Muskelsystems Nittshin Igaku 1961; 48:137-145. (in Japanese)

21) Sasagawa I, Takahashi $K$, Igarashi $A$, Mori $H$ and Kobayashi $K$. A case of the abnormal bundle from the anterior margin of the right and left trapezius and the abnormality in the right omohyoid appeared in a cadaver. Shigaku. 1982; 70: 439-448. (in Japanese with English abstract)

22) Sato $Y$, Oota $Y$ and Yokota A. La anomalio de $M$. omohyoideus cê japanoj. Nichidai Igaku. Z. 1969; 28:431444. (in Japanese with Esperanto abstract)

23) Steinbach $K$. Über Varietäten der Unterzungenbein-und Brustmuskulatur. Anat. Anz. 1923; 56:488-506.

24) Takano $T$, Takaya $M$, lizuka $K$, Togazawa $T$ and Adachi. A statistical study of abnormal muscle of infrahyoid. Iwateidai Kaibou Gyouseki. 1955; 2:113-124. (in Japanese)

25) Takisawa $\mathrm{A}$. On the development of $\mathrm{m}$. omo-hyoideus Acta Anat. Nippon 1971; 46:21. (in Japanese)

26) Takisawa A. On the development of anuran omohyoid muscle during metamorphosis. Acta Anat. Nippon. 1973; 
48:330-340. (in Japanese with English abstract)

27) Testut L. Les anomalies muscularies chez l'homme. 236241, Masson, Paris, 1884.

28) Totinai $I$ and Aonuma $T$. Abnormal muscles of cleidohyoid and omohyoid. Iwate Igk. Z. 1944; 7:2-8. (in Japanese)

29) Virchow H. Ueber die tiefen Huckenmuskeln des Menschen, Vorschläge zun Abänderung der Bezeichnung derselben, Verhandl Anat Gesellschaft 21. Versammlung Würzburg, 1907. (cited from Eisler)

30) Wagenseil F. Untersuchungen über die Muskulatur der Chinesen. Zeitschr f Morph. u. Anthrop. 1937; 36:39-96.

31) Windle BCA. Notes of some nervous and muscular variation. J. Anat. and Physiol. 1887: 21. (cited from Eisler)

32) Yamada $\mathbf{H}$ and Nishijima T. A rare case of abnormity in the m. omohyoideus. Kyushu Shika Z. 1954; 11:187-188. (in Japanese with English abstract)

33) Yamada $H$, Kuga $H$ and Ozumi $K$. Case report of abnormities in $\mathrm{M}$. omohyoideus and $\mathrm{M}$. sternothyroideus. Kyushu Shika Z. 1960; 14:390-394. (in Japanese with English abstract)

34) Yamada $M$ and Mannen $H$. Manual of human dissection. 1st ed., 15-21, Nankohdo, Tokyo, 1985. (in Japanese)

35) Yamada S. Über einige Variationen der $\mathrm{Mm}$. infrahyoidei und Anomalien des clavicularen Ansatzes des M. Trapezius on den japanischen Foeten und Neugeborenen. Acta Anat. Nippon 1934; 7:337-347. (in Japanese)

36) Yonekura S. A study of the muscles of the neck chest, abdomen and back in Japanese fetuses. Igaku Kenkyu 1954; 24:1604-1700. (in Japanese with English abstract)

37) Yoshizuka $M$, Tanaka I, Sakamoto $F$, Hirata $T$ and Miyazaki M. An abnormal case of musculus omohyoideus. Kurume Igaku Z. 1987; 50:375-378. (in Japanese with English abstract) 


\section{Explanation of Figures}

\section{Plate I}

Fig. 2. Ventral view of the right anterior region of the neck. The sternocleidomastoid muscle ( $\mathrm{Scm}$ ) was cut off at the proximal origin and is reflected lateralwards. The clavicle and the parotid gland are already removed. An anomalous muscle (AOH) can be seen under the usual right omohyoid muscle (OHS, OHI). Small pieces of black paper (arrow) indicate the location of the nerve supply of this muscie. The bridge fasciculus (arrowhead) from the superior belly (OHS) of the usual omohyoid muscle can be seen between the omohyoid superior belly and the anomalous muscle. 


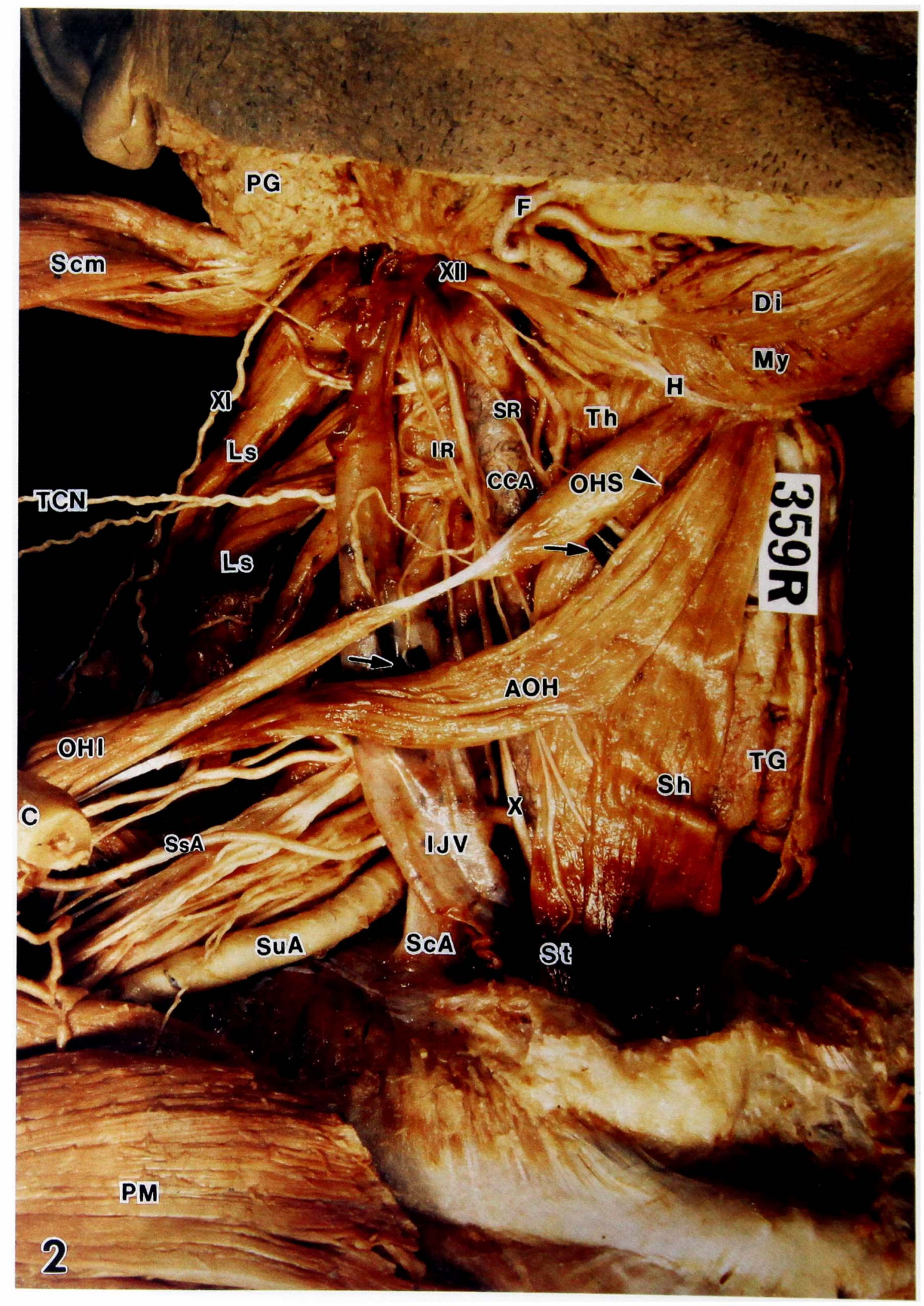




\section{Plate II}

Fig. 3. Dorsal view of right posterior region of the neck and shoulder. The trapezius ( $\mathrm{T}$ ) and supraspinatus (Ss) muscles are cut at each origin and each muscle is reflected toward the cranial side so as to expose the origin of the anomalous muscle (asterisk) (arrow). The medial upper portion of the scapula $(\mathrm{Sc})$ can be seen.

Fig. 4. Relationship on the dorsal side between both the origin of an anomalous and a usual omohyoid muscle. The portion of origin of the anomalous and the usual omohyoid muscle are dissected out in the form of one specimen-block. The arrow indicates the portion of origin of the anomalous muscle. 

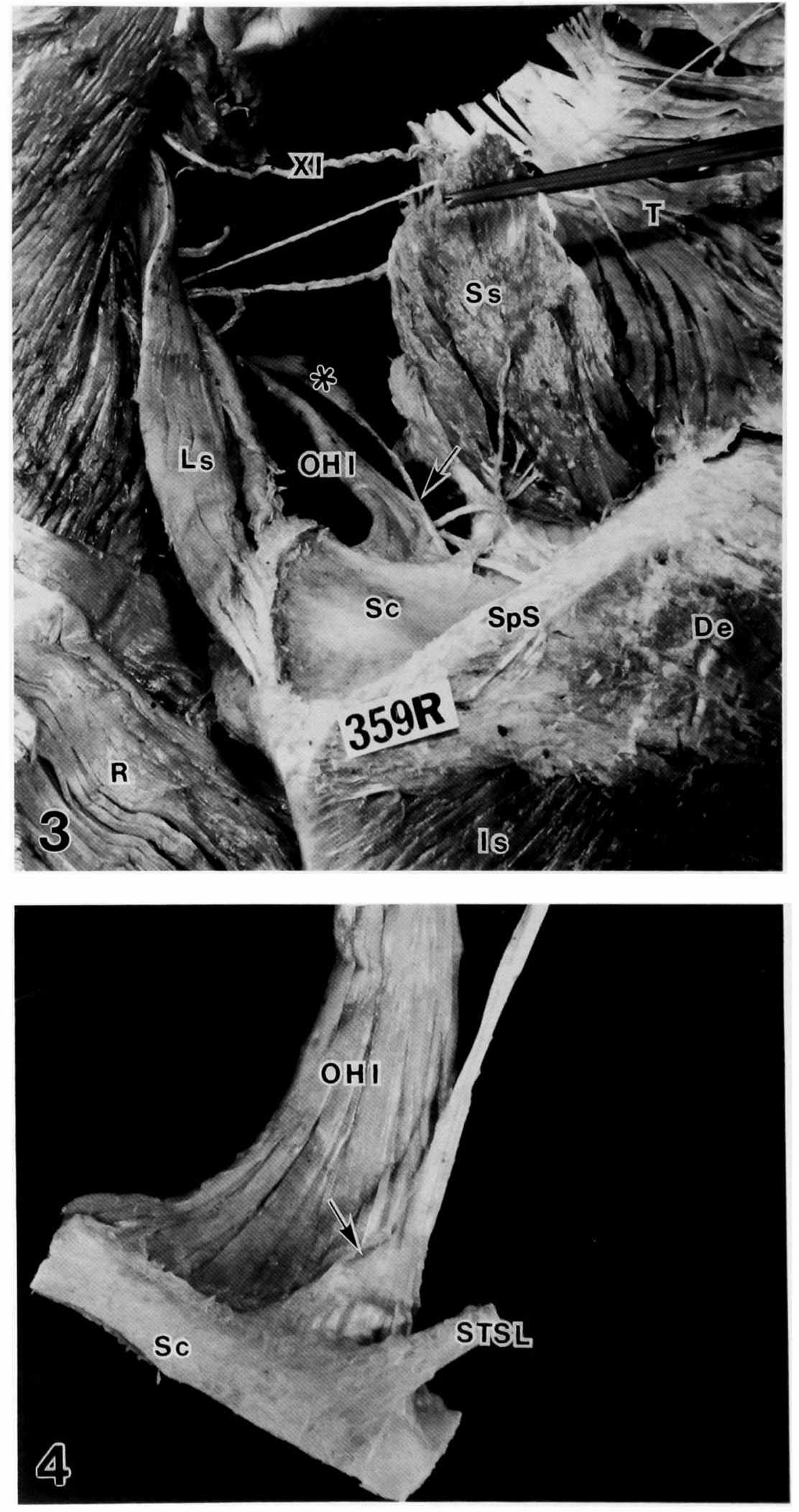


\section{Plate III}

Figs. 5a and b. Ventral view of the insertion portion of an anomalous muscle (AOH). The superficial fasciculus (SF) is reflected medialward so as to expose the profound fasciculus (PF) (the photograph: $a$ and the drawing: $b$ ). A small tendinous arch (arrow) can be seen in the area where the anomalous muscle fuses with the sternohyoid muscles. The infrahyoid muscles and their nerves are dissected out. 

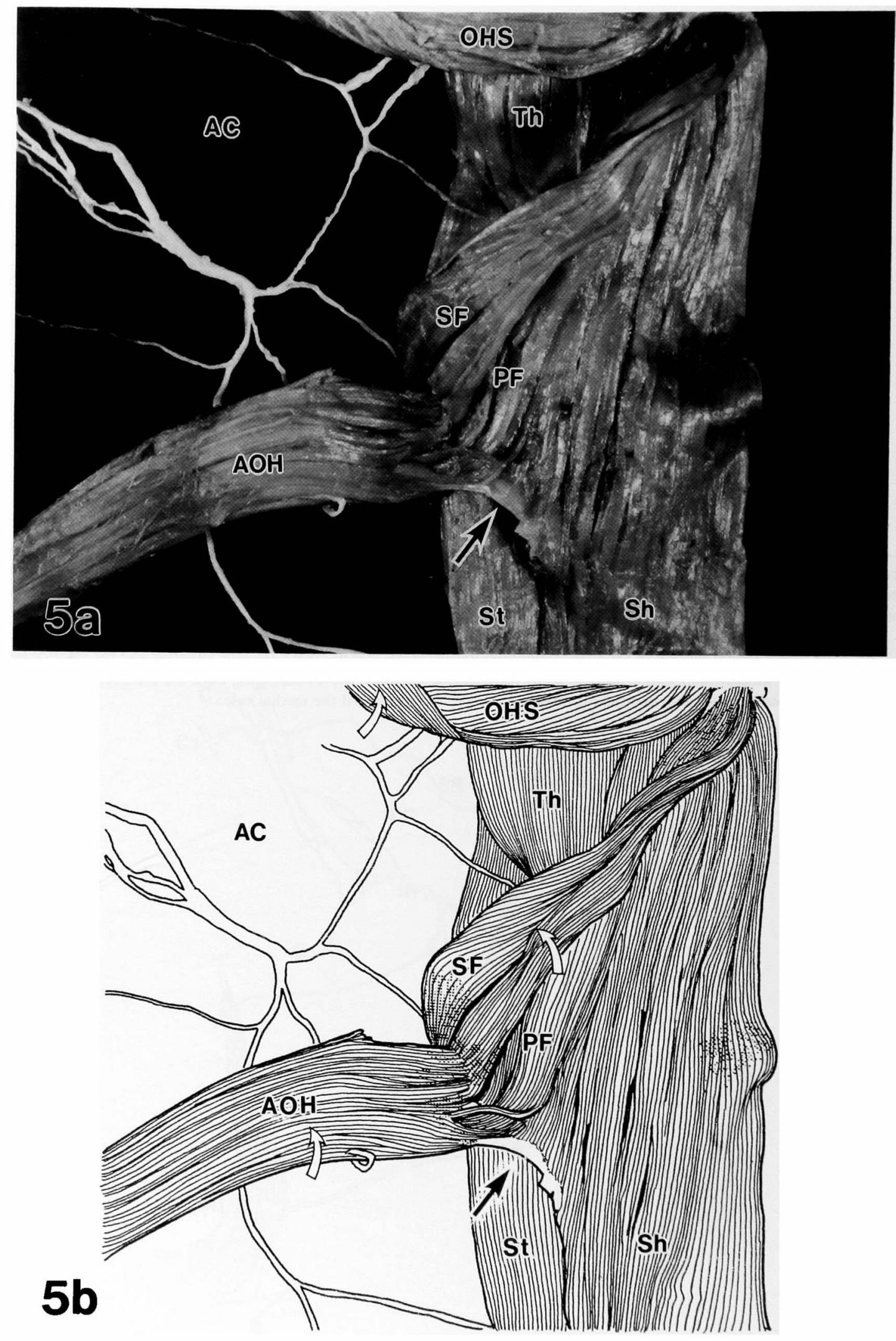


\section{Plate IV}

Figs. 6a and b. The infrahyoid muscles and an anomalous muscle ( $\mathrm{AOH})$ found in this study are dissected out in the form of a nervemuscle specimen. The omohyoid (OHS, OHI), sternohyoid (SH), sternothyroid ( $\mathrm{St}$ ), thyrohyoid (Th) and the anomalous muscle innervated by the ansa cervicalis and the hypoglossal nerve (XII) can all be seen from the ventral side (the photograph: a and the drawing: $b$ ).

a: The infrahyoid muscles and their nerves together with part of the scapula and the hyoid bone are removed.

b: The intermediate tendon of the usual omohyoid muscle is cut and its each belly (the superior and the inferior belly) are reflected medial- and lateralward so as to fully expose both the nerves supplying both the infrahyoid muscles and the anomalous muscle. The anomalous muscle is also reflected toward the medial side. 

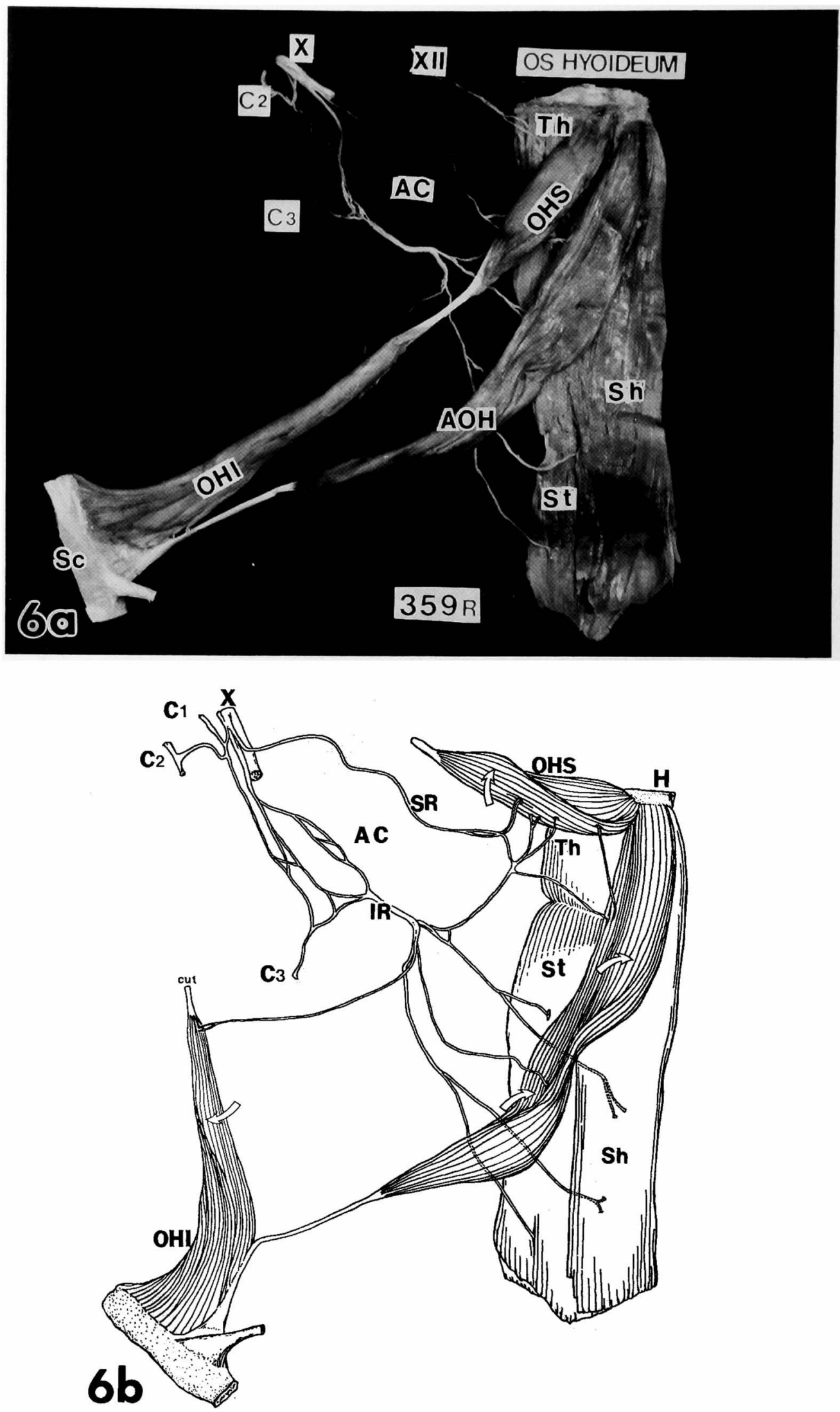


\section{Plate V}

Fig. 7. Diagram showing the intramuscular nerve distribution of this case (ventral view). The superficial fasciculus (SF) of the distal portion of an anomalous muscle is reflected toward the medial side. The superior belly (OHS) of the usual omohyoid muscle is reflected toward the cranial side. The anomalous muscle is supplied by two twigs (A, B) from both the superior and the inferior root of the ansa cervicalis. But, there is no communication between these roots.

*: a nerve branch to bridge fasciculus from the omohyoid superior belly.

**: communication branch between both filaments from the superior root $(\mathrm{A})$ and nerve branches in the superior belly of the omohyoid muscle. 
Double Omohyoid Muscle $\begin{array}{r}97 \\ \text { Plate V }\end{array}$

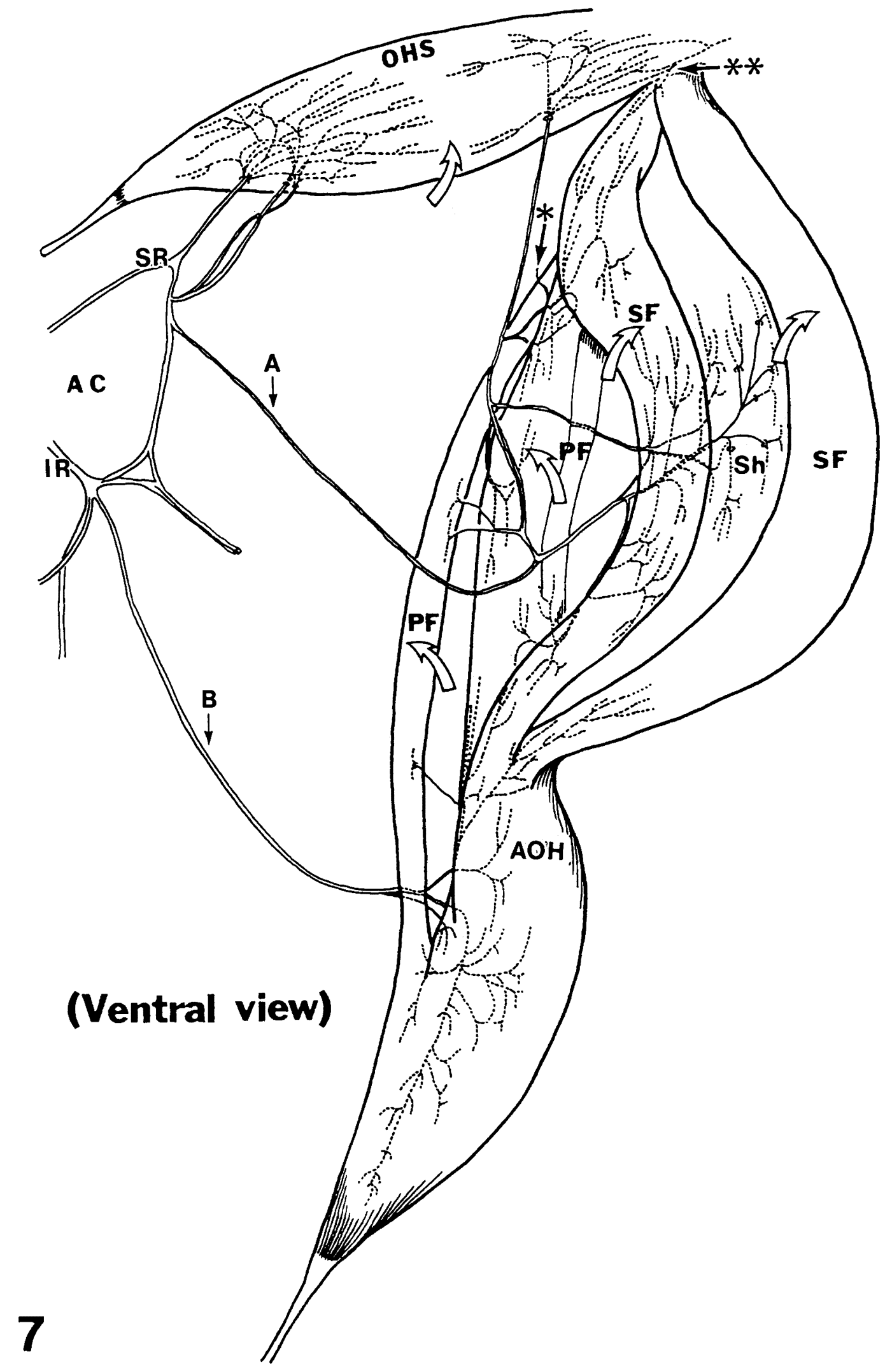

